Research Article

\title{
A comparative study on efficacy and safety profile of risperidone and iloperidone in patients of schizophrenia: randomized controlled study
}

\author{
Swathi Acharya ${ }^{1}$, V. Srinivasa ${ }^{2}$, S. Kotresh ${ }^{3}$, Sharanappa Mulimani $^{4}$, \\ Anithraj Bhat ${ }^{5}$, Manohar Bhat ${ }^{6}$
}

${ }^{1}$ Department of Pharmacology, K.S. Hegde Medical Academy, Deralakatte, Mangalore, India

${ }^{2}$ Department of Pharmacology,

${ }^{3}$ Department of Psychiatry,

Vijayanagara Institute of

Medical Sciences, Ballari, India

${ }^{4}$ Department of Pharmacolgy,

Koppal Institute of Medical

Sciences, Koppal, Karnataka,

India

${ }^{5}$ Department of Radiology,

SDM medical college and

research centre, Dharwad,

Karnataka, India

${ }^{6}$ Department of Public Heath

dentistry, KVG Dental College,

Sullia, Karnataka, India

Received: 06 April 2016

Accepted: 07 May 2016

*Correspondence to:

Dr. Swathi Acharya,

Email: acharyaswathi4

@gmail.com

Copyright: (C) the author(s), publisher and licensee Medip Academy. This is an openaccess article distributed under the terms of the Creative Commons Attribution NonCommercial License, which permits unrestricted noncommercial use, distribution, and reproduction in any medium, provided the original work is properly cited.

\begin{abstract}
Background: Antipsychotics are most commonly used as first line therapy for schizophrenia. Treatment with antipsychotics is marked by poor compliance, drug discontinuation and frequent switching attributable to lack of efficacy of recently introduced atypical antipsychotics. The objectives of this study was to compare the efficacy and safety profile of risperidone, most commonly used drug with iloperidone, a recently introduced antipsychotic.

Methods: In this prospective, randomized open label 6-week study, 80 patients with diagnosis of Schizophrenia were randomized to two groups to receive either risperidone (4-8 $\mathrm{mg}$ ) or iloperidone $(6-24 \mathrm{mg})$. Their efficacy was assessed using reduction in PANSS score and safety profile was assessed by monitoring the adverse effects during follow-up visits at 2, 4, 6 weeks.

Results: Efficacy parameter, PANSS score showed significant reduction in both groups as compared to baseline values after 6 weeks. But there were no significant differences between two groups. The safety profile assessed by comparison of adverse effects showed statistically significant differences between the groups $(<0.01)$.

Conclusions: Iloperidone with better extrapyramidal side effect profile and equivalent efficacy can be considered as good alternative to risperidone in schizophrenia treatment.
\end{abstract}

Keywords: Risperidone, Iloperidone, Schizophrenia

\section{INTRODUCTION}

Schizophrenia is a mental disorder, characterized by disruptions in thinking, affects the language, perception, and the sense of self and includes psychotic experiences, such as hearing voices or delusions. It affects mainly the adults in the age group of 15-35 years. The incidence is low $(3-10,000)$ but the prevalence is high due to 
chronicity. There are about 21 million people affected worldwide due to schizophrenia. ${ }^{1}$

In India there are an estimated 4.3 to 8.7 million people with schizophrenia. ${ }^{2}$ Persons suffering from Schizophrenia, have $20 \%$ shorter life expectancy due to increased morbidity and mortality. ${ }^{3}$ schizophrenia in up to 80 percent of youths due to combination of factors like isolating oneself and withdrawing from others, an increase in unusual thoughts and suspicions, and a family history of psychosis. ${ }^{4}$ It is a leading contributor to global and regional levels of disability due to its chronic course and clinical, social and economic consequences on society. The economic impact is due to early onset, chronic course, excess mortality, frequent re-admissions to hospitals, and high rate of disability. Discrimination is created towards the persons with schizophrenia leads to social isolation, unemployment, institutionalisation or even homelessness that further decrease the chances of recovery. ${ }^{5}$

Schizophrenia is a treatable disorders, treatment is more effective in its initial stages. The high mortality rate in schizophrenic patients is attributed to greater risk of developing obesity, type 2 diabetes, hypertension and dyslipidemia and cardiovascular illness. ${ }^{6}$ Antipsychotic drugs are the cornerstone for the treatment of schizophrenia. The initial introduced first-generation "conventional" antipsychotic drugs, had drawback of causing high rates of neurologic side effects, such as extrapyramidal signs and tardive dyskinesia. ${ }^{7}$ Which led to the discovery of second-generation, or "atypical," antipsychotic drugs which have enhanced efficacy and safety. ${ }^{8}$ Among the atypical antipsychotics, risperidone, the most widely studied drug, has shown to improve positive and negative symptoms of psychosis with reduced risk of relapse and lower liability for movement disorders. ${ }^{9}$ Still there is 4 to $8 \%$ of EPS associated with the use of risperidone which is the reason to reduce the compliance of the patient to the treatment. ${ }^{10}$

Iloperidone, a new dopamine type2/serotonin type $2 \mathrm{~A}$ (D2/5HT2A) antagonist structurally related to risperidone, is expected to give better efficacy with lesser extrapyramidal symptoms than the D2 receptor antagonists. ${ }^{11}$ It has potent antipsychotic activity and efficacy in treating neurocognitive deficits, anxiolytic effects, and favourable tolerability, including low propensity to cause EPS or weight gain. ${ }^{12}$ Hence the study was planned to compare the efficacy and safety profile of risperidone with iloperidone.

\section{METHODS}

The present study was prospective, randomized and open label study conducted in Vijayanagar Institute of Medical Sciences, Bellary, Karnataka, India patients attending outpatient department of psychiatry were enrolled into the study. The study was conducted for a period of one and half year.
The institutional ethics committee approval was taken before starting the study. The patients were explained about the study details. Written/informed consent was taken from all patients before subjecting them to study. In case of patients with acute symptoms lacking insight, the consent was taken from immediate attendant during the enrolment into the study. Later during the treatment process when the patient condition was improved he/she was explained about treatment given and the consent was taken again.

The inclusion criteria were followed to include both male and female patients diagnosed with Schizophrenia according to ICD-10 criteria in between the age group of 18 to 65 years. Exclusion criteria: Pregnant and lactating females, Patients with history of hypertension, diabetes, hypercholesterolemia and cardiac diseases, hepatic disease, renal disease and terminally ill patients, Patients with organic brain syndromes and drug abuse, patients already on other antipsychotic agents.

Sample size was determined to be 40 in each group. Hence total 80 patients were included in the study detailed history and detailed psychiatric assessment was done for all the patients. The enrolled patients were divided into both the groups by block randomisation method. One group was given tablet risperidone (4-8 $\mathrm{mg}$ /day) and another group tablet iloperidone (6-24 $\mathrm{mg} /$ day).

The patients were given treatment for 6 weeks. Periodic psychiatric assessment for efficacy, safety parameters of both antipsychotics were done at every 2 weeks. Efficacy was assessed by measuring the reduction in the total PANSS scores at the end of the study ( $6^{\text {th }}$ week) from baseline scores.

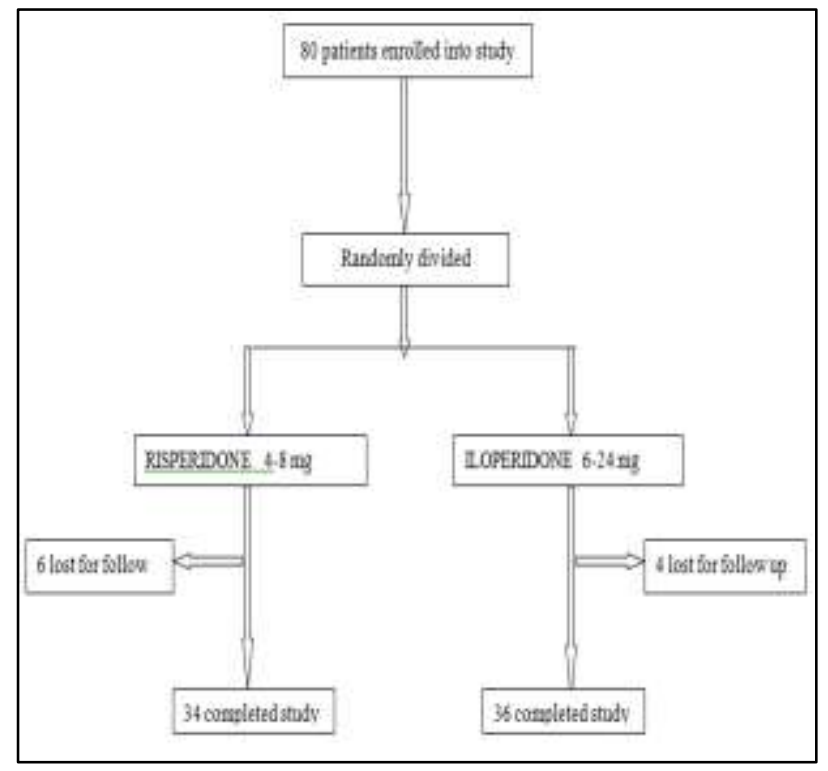

Figure 1: Flow diagram of participants from enrolment to term. 
The safety profile was assessed by comparing the adverse effects in the patients of both groups with a standard adverse check list prepared based on previous literature, for the study. Total 10 patients did not turn up for follow up which involved 6 from risperidone group and 4 from iloperidone group. Study was completed in 70 patients (Figure 1).

Statistical analysis using the statistical package - SPSS version 20 was done. Descriptive statistical analyses were performed. Comparisons between groups were performed with the use of an independent sample student' $t$ ' test and paired ' $t$ ' test for continuous variables, chi square test for categorical variables.

\section{RESULTS}

In risperidone group including 19 male and 15 female patients, the mean PANSS reduction of PANSS score from baseline till $6^{\text {th }}$ week was $84.98 \pm 10.18$. The efficacy rate was $57.30 \%$, where as in iloperidone group including 22 males and 14 female patient's reduction in PANSS score from baseline to the end of $6^{\text {th }}$ week was $86.32 \pm 10.48$. The efficacy rate was $58.90 \%$. Efficacy was compared between the groups by using Independent $t$ test which showed there was no significant difference $(\mathrm{p}<0.245)$.

The safety profile assessed by comparing the adverse effects showed patients in risperidone group had higher incidence of extrapyramidal side effects like bradykinesia $(35 \%)$, tremor $(32.3 \%)$, rigidity $(20.5 \%)$, akathisia (14.7\%), dystonia (9\%) compared to iloperidone groups where incidence of dizziness (33.3\%), somnolence
(33.3\%), tachycardia (16.6\%), postural hypotension $(14.7 \%)$ was higher. There was a statistical significant difference in the incidence of bradykinesia and tremor $(\mathrm{p}<0.05)$ in risperidone group. Dizziness was significantly observed in iloperidone group.

\section{DISCUSSION}

In total, among the 70 patients who completed the study, 49 patients were in the $18-40$ years age group. The higher prevalence of schizophrenia in these age groups indicates the link between stress factors. Out of the 70 patients who completed the study, 41 were males (19 in risperidone group and 22 in iloperidone group) and 29 were females (15 in risperidone group and 14 in iloperidone group) (Table 1).

Some of the clinical and epidemiological studies suggests that there is no gender difference for incidence of schizophrenia which was contrasted by the results of recent meta-analysis and systemic reviews suggesting males are at higher risk for schizophrenia compared to females. ${ }^{13,14}$ A study done in Madras also showed same result with higher rate seen in males and in the age range of $15-45$ years. 15

Though the specific reasons for this are unknown, the possibility that schizophrenia may go unrecognized to a larger extent in women than in men and course of the illness tends to be more severe in men than in women that would be reflected in a higher prevalence in males. ${ }^{16}$ Women tend to have a later age of onset which is postulated to be the effects of oestrogen on reduced sensitivity of D2 receptors in the central nervous system. ${ }^{17}$

Table 1: Age and sex distribution of risperidone and iloperidone study group.

\begin{tabular}{|lllll|}
\hline Age group (years) & Male & Risperidone & Male & \multicolumn{1}{c|}{ Female } \\
\hline $18-29$ & $05(15 \%)$ & $05(14 \%)$ & $08(22 \%)$ & $06(17 \%)$ \\
\hline $30-39$ & $07(20 \%)$ & $06(18 \%)$ & $07(19 \%)$ & $05(14 \%)$ \\
\hline $40-49$ & $03(9 \%)$ & $02(6 \%)$ & $04(11 \%)$ & $02(6 \%)$ \\
\hline $50-59$ & $03(9 \%)$ & $01(3 \%)$ & $03(8 \%)$ & $01(3 \%)$ \\
\hline$>\quad 60$ & $01(3 \%)$ & $1(3 \%)$ & 0 & 0 \\
\hline Total & $19(56 \%)$ & $15(44 \%)$ & $22(60 \%)$ & $14(40 \%)$ \\
\hline
\end{tabular}

Table 2: Comparison of efficacy of risperidone and iloperidone study groups.

\begin{tabular}{|lllclc|}
\hline Study groups & \multicolumn{5}{c|}{ (MEAN \pm SD) of PANSS score. } \\
& Baseline score & End of 6 week & $\begin{array}{l}\text { Reduction of PANSS } \\
\text { score within 6 weeks }\end{array}$ & $\begin{array}{l}\text { Efficacy rate } \\
\text { in \% }\end{array}$ & $\begin{array}{l}\text { Statistical } \\
\text { significance }\end{array}$ \\
\hline Resperidone & $148.45 \pm 12.557$ & $63.47 \pm 10.285$ & $84.98 \pm 10.177$ & $57.30 \%$ & $\mathrm{t}=0.898(\mathrm{P}-0.245)$ \\
Iloperidone & $146.40 \pm 15.170$ & $60.08 \pm 13.572$ & $86.32 \pm 10.480$ & $58.90 \%$ & p $>0.05$ not significant \\
\hline
\end{tabular}


Table 3: Comparison of safety profile of risperidone and iloperidone study groups.

\begin{tabular}{|llllll|}
\hline Adverse effect & Risperidone & $\%$ & Iloperidone & $\%$ & Statistical significance \\
\hline Insomnia & 04 & 12 & 04 & 11.1 & - \\
\hline Bradykinesia & 12 & 35 & 02 & 5.5 & 0.003 \\
\hline Tremor & 11 & 32.3 & 03 & 8.3 & 0.018 \\
\hline Rigidity & 07 & 20.5 & 02 & 5.5 & - \\
\hline Dystonia & 03 & 9 & 00 & 00 & - \\
\hline Headache & 03 & 9 & 02 & 5.5 & - \\
\hline Anxiety & 02 & 6 & 01 & 2.7 & - \\
\hline Constipation & 06 & 15 & 03 & 8.3 & - \\
\hline Dry mouth & 05 & 17.6 & 05 & 14.7 & - \\
\hline Tachycardia & 02 & 6 & 06 & 16.6 & - \\
\hline Akathisia & 05 & 14.7 & 00 & 00 & - \\
\hline Fatigue & 04 & 11.7 & 03 & 8.3 & - \\
\hline Weight gain (>7\%) & 04 & 11.7 & 02 & 5.5 & - \\
\hline Dyspepsia & 04 & 11.7 & 01 & 2.7 & - \\
\hline Agitation & 01 & 3 & 00 & 00 & - \\
\hline Nasal congestion & 00 & 0 & 01 & 2.7 & - \\
\hline Postural hypotension & 01 & 3 & 05 & 14.7 & - \\
\hline Increased appetite & 04 & 11.7 & 03 & 8.3 & - \\
\hline Dizziness & 05 & 17.6 & 12 & 33.3 & 0.055 \\
\hline Somnolence & 08 & 23.5 & 12 & 33.3 & - \\
\hline Arthralgia & 00 & 00 & 02 & 5.5 & - \\
\hline Urinary incontinence & 00 & 00 & 00 & 00 & - \\
\hline Impotence & 00 & 00 & 00 & 00 & - \\
\hline Flatulence & 00 & 00 & 00 & 00 & - \\
\hline Dyskinesia & 00 & 00 & 00 & 00 & - \\
\hline
\end{tabular}

Comparison of efficacy showed iloperidone having an efficacy rate of $58.90 \%$ which was slightly more than that of risperidone $(57.30 \%)$. However when both the groups were compared the difference in the efficacy rate was not statistically significant $(\mathrm{P}>0.05)$ (Table 2, Figure 2).

The efficacy of iloperidone was compared with that of risperidone in several placebo- controlled studies suggested that iloperidone was more effective than placebo and as effective as risperidone in treating schizophrenia and it has efficacy equivalent to that of the risperidone at the dose range of 6-8 $\mathrm{mg} / \mathrm{day}{ }^{18}$

The safety profile of both antipsychotics were evaluated by comparing them with the standard adverse effects check list prepared for the study, based on previous studies and literature. Accordingly, risperidone caused more of bradykinesia (35\%), tremor $(32.3 \%)$, somnolence $(23.5 \%)$, rigidity $(20.5 \%)$, dizziness $(17.6 \%)$, constipation $(15 \%)$, akathisia $(14.7 \%)$, fatigue $(11.7 \%)$, significant weight gain $(11.7 \%)$, dyspepsia $(11.7 \%)$, increased appetite $(11.7 \%)$, dystonia (9\%), head ache $(9 \%)$, anxiety $(6 \%)$, agitation (3\%) than iloperidone. The incidence of extrapyramidal side effects was significantly higher in the risperidone group. Dizziness (33.3\%), somnolence (33.3\%), tachycardia (16.6\%), postural hypotension
(14.7\%), arthralgia (5.5\%), nasalcongestion (2.7\%) were seen more in iloperidone group (Table 3).

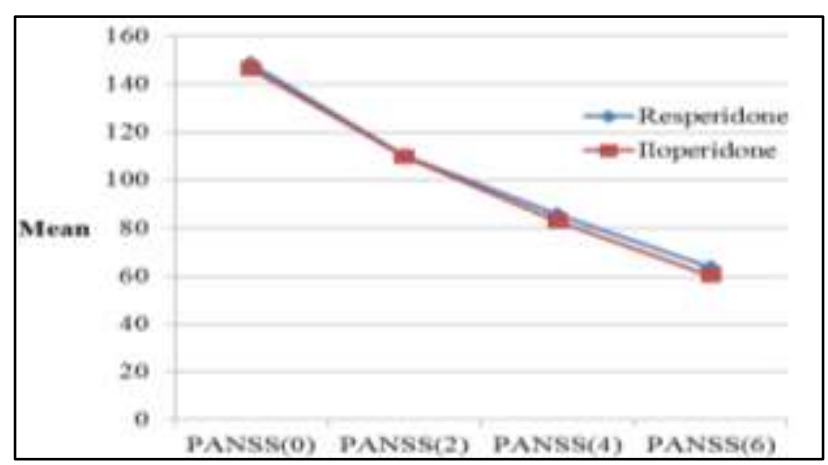

Figure 2: PANSS between two groups. 


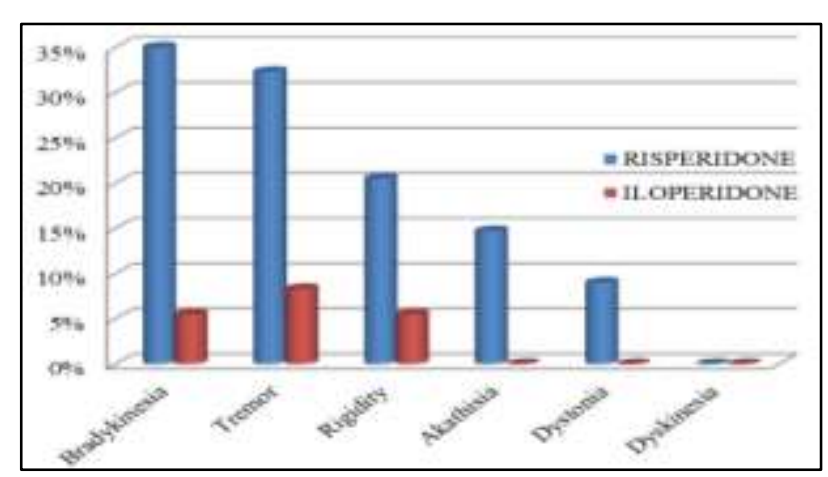

Figure 3: Extrapyramidal adverse effects.

Bradykinesia, tremor, rigidity, somnolence occurred among maximum number of patients in risperidone group among which incidence of bradykinesia and tremor were significantly high $(\mathrm{p}<0.05) \quad($ Figure 2). Dizziness, somnolence, tachycardia occurred more in iloperidone group. Dizziness was significantly high (Figure 3).

The short term studies done comparing iloperidone, risperidone and placebo suggested that the most common adverse effect in all groups of iloperidone were dizziness, dry mouth, somnolence and dyspepsia in contrast with risperidone were extrapyramidal disorder, akathisia, tremor and somnolence. The incidence of orthostatic hypotension was greater with iloperidone compared to risperidone within the first week of treatment which was not sustained. $78.6 \%$ of the patients were manifested with atleast one side effect in iloperidone group and $78.4 \%$ in risperidone group. ${ }^{19}$

Weight gain was seen in both the groups with the risperidone group showing a mean weight gain of $2.06 \mathrm{~kg}$ and $1.01 \mathrm{~kg}$ for iloperidone group. However, when significant weight gain was considered (defined as an increase in at least $7 \%$ of body weight from baseline), 4 patients $(10 \%)$ in risperidone group in contrast with 2 $(5 \%)$ in iloperidone group showed significant weight gain.

The studies shows that both iloperidone and risperidone showed the small statistically significant weight gain compared to placebo with mean increase of $1.5 \mathrm{~kg}$ in both the groups. ${ }^{19}$ However long term efficacy trails suggests that weight gain plateaues after initial period in iloperidone group. ${ }^{20}$

\section{CONCLUSION}

The efficacy of iloperidone, a novel D2/5HT2A antagonist, is comparable to that of risperidone, most commonly used atypical antipsychotic. Iloperidone showed slightly better tolerability than risperidone in patients with schizophrenia. The incidence and severity of extrapyramidal adverse effects was higher with risperidone. However further studies have to be performed by conducting multi-centric clinical studies comparing these two antipsychotics with a larger sample size and for longer duration.
Funding: No funding sources Conflict of interest: None declared

Ethical approval: The study was approved by the Institutional Ethics Committee

\section{REFERENCES}

1. WHO. Factsheet: Schizophrenia, 2015. Available at http://www.who.int/topics/schizophrenia/en.

Accessed 20 November 2015.

2. Schizophrenia Facts and statistics. Available at http://www. schizophrenia.com/Szfacts.htm. Accessed 20 November 2015.

3. Shiv G, Parth SM. Drug emergent metabolic syndrome in patient with schizophrenia receiving atypical antipsychotics. Indian Journal of Psychiatry. 2011;53(2):109-16.

4. Cannon TD, Cadenhead K. Prediction of psychosis in high-risk youth: a multi-site longitudinal study in North America. Archives of General Psychiatry. 2008;65(1):28-37.

5. Wulf RB, Hans JS, Jim van OS, Anita RR. Size of burden of schizophrenia and psychotic disorders. Europea Neuro Psycho Pharmacology. 2005;15:399-409.

6. Lambert TJ, Velakoulis D, Pantelis C. Medical comorbidity in schizophrenia. Med $\mathrm{J}$ Aust. 2003;178:67-70.

7. Miyamoto S, Duncan GE, Marx CE, Lieberman JA. Treatments for schizophrenia: a critical review of pharmacology and mechanisms of action of antipsychotic drugs. Mol Psychiatry. 2005;10:79-104.

8. Kane J, Honigfeld G, Singer J, Meltzer H. Clozapine for the treatment resistant schizophrenic: a doubleblind comparison with chlorpromazine. Arch Gen Psychiatry. 1988;45:789-96.

9. Donal EN, Addington. Efficacy and tolerability of ziprosidone versus risperidone in patients with acute exacerbation of schizophrenia or schizoaffective disorder: an 8 weeks double blind multicenter trial. J clinical psychiatry. 2004;65:12

10. Lieberman JA, Stroup TS, McEvoy JP. Effectiveness of antipsychotic drugs in patients with chronic schizophrenia. N Engl J Med. 2005;353:1209-23.

11. Silvio C, Luca P, Alless AN. New atypical antiphyschotics for schizophrenia: iloperidone. Drug Des Devel ther. 2010;4:33-48.

12. Kalkman HO, Subramanian N, Hoyer D. Extended radioligand binding profile of iloperidone: a broad spectrum dopamine/serotonin/norepinephrine receptor antagonist for the management of psychotic disorders. Neuro Psycho Pharmacology. 2001;25:904-14.

13. John MG, Sukanta S, Joy W, Ossama ES, Clare MC, David C. A systematic review of the incidence of schizophrenia: the distribution of rates and the influence of sex, urbanicity, migrant status and methodology. BMC Medicine. 2004;2:13. 
14. Andr A, Ren SK, Jean-PS. Sex differences in the risk of schizophrenia; evidence from meta-analysis. Arch Gen Psychiatry. 2003;60(6):565-71.

15. Parmanand K, Ruchita S, Aarya KR. An overview of Indian research in schizophrenia. Indian J Psychiatry. 2010;52(1):159-72.

16. Sukanta S, David C, Joy W, John MG. A systematic review of the prevalence of schizophrenia. PLos medicine. 2005;2(5):141:413-32.

17. Häfner H, Löffler W, Maurer K, Hambrecht M, An der Heiden W. Depression, negative symptoms, social stagnation and social decline in the early course of schizophrenia; Acta Psychiatrica Scandinavica. 1999;100:105-18.
18. Steven GP, Robert EL, Rosarelis T, Curt DW. Efficacy of iloperidone in the treatment of schizophrenia initial phase 3 studies. Journal of Clinical Psychopharmacology. 2008;28(2);4-11.

19. Peter JW, Andrew JC, Mihael HP, Curt DW. Safety profile of iloperidone a pooled analysis of 6-week acute-phase pivotal trials. J Clin Psychopharmacol. 2008;28:12-9.

20. John MK, John L, Eugene L, Michael DM, Curt DW. Long-term efficacy and safety of iloperidone results from phase 3 clinical trials for the treatment of schizophrenia. J Clin Psychopharmacol. 2008;28:29-35.

Cite this article as: Acharya S, Srinivasa V, Kotresh S, Mulimani S, Bhat A, Bhat M. A comparative study on efficacy and safety profile of risperidone and iloperidone in patients of schizophrenia: randomized controlled study. Int J Basic Clin Pharmacol 2016;5:1062-7. 